\title{
Histological Review of Benign Prostatic Hyperplasia in Southern Tertiary Hospital of Nigeria from Jan 2005-Dec2012.
}

\author{
Martin nnoli (1), Godwin Ebughe(1), Omotosho,Ayodele Joshua(1), \\ Nwabara victor I.(2) \\ ${ }^{1}$ University of Calabar Teaching hospital, dept of Pathology \& Forensic Medicine, Calabar. \\ ${ }^{2}$ University of Calabar Teaching hospital,dept of surgery, Calabar.
}

\begin{abstract}
:
Aims and Objectives: This is to determine the age range of the lesion within our study;as a way to suggest possible recommendation(s).

Materials/Methods: A sectional study of results of 463 patients within the study year(Jan 2005-Dec 2012) was obtained from the Dept. of Pathology register of the university of calabar Teaching hospital Calabar. These were analyzed using SPSS version 16 per each year. The result was represented in bar chats and pie chats respectively.

Results: It showed that the ages of 50-60 years and 60-70 years are the worst vulnerable in the lesion(enlargement of prostrate) with its consequences of obstruction during micturition. Above the age of 70 years; only showed a significant rise in 2012 with $22 \%$ of patients indicated.

Conclusion/recommendation: A better understanding of all risk factors (increasing age as per negroid race) and rates of clinical progression of benign prostatic hyperplasia (BPH) should be advocated - in terms of medical education of the citizenry. Since urinary retention is one of the most usual and important complications of long term BPH as this calls for both conservative and surgical therapy.

Keywords: Male, benign prostatic hyperplasia, histology
\end{abstract}

\section{Introduction:}

Benign Prostatic hyperplasia (BPH) is usually a common disorder in most men over age of 50 years and is characterized by prostatic hyperplasia of the stromal components and epithelial cells. These results to formation of large,fairly discrete nodules in the peri-urethral region of the prostrate. These nodules grows to compress and narrow the urethral canal causing partial or at times complete obstruction of urether. ${ }^{1}$ Histologic evidence of BPH could be seen with aging: as prevalence varies from $20-25 \%$ among men of 40 to 49 years of age. ${ }^{1,2}$ This is increases to $80 \%$ among $70-79$ years of age. ${ }^{2}$ Many men with histologic findings of BPH and anatomically enlarged prostrate have no symptoms; but more than $50 \%-70 \%$ of men are in $60 \mathrm{~s}$ and $90 \%$ are octogenarians. The later presenting with lower urinary tract symptoms with lower urinary symptoms. ${ }^{3}$ However, in USA, about 14 million men has lesion of BPH; as this increases with age. It is observed that $25 \%$ of men older than 40 years has such symptoms of BPH. This increases to $1 / 3$ of men older than 65 years. ${ }^{4}$ This prevalence increases from moderate to severe symptoms from $13 \%$ in men in their 40 s to $28 \%$ in older than 70 years of age. $^{3}$

In Berry SJ et al studies - they observed that prevalence of pathological BPH occurs at $8 \%$ in $4^{\text {th }}$ decade; but $50 \%$ of male population has pathological BPH when they are 51-60 years old. They average weight of the prostrate seen at autopsy is 33 plus or minus $16 \mathrm{gm}$;about $4 \%$ at age greater than 70 years old reaches greater than more than $100 \mathrm{gm}$. These shows that BPH growth in men 31 and 50 years old doubles by 4.5 years and mid-phase growth at 51 and 70 years doubling is in about 10 years as this increases greater than 100 years beyond 70 years old. ${ }^{2}$

Other etiological factors have been associated with BPH apart from older age and normal androgenic function with a prostrate family history. Factors like race, geographic location, cigarette smoking and male pattern of baldness have also been implicated. ${ }^{5,6}$ Similar report by steve A. Kaplan showed that a few things may cause lower urinary tract symptoms which could be urologic and non urologic states; mediators that increases obstructive urinary symptoms, obesity, regular alcohol consumption, and elevated blood pressure all could lead to benign prostatic hyperplasia. ${ }^{7,8}$ This is supported too in Aruna v. sarma et al studies were they alluded that black ${ }^{9}$, obesity ${ }^{10}$, diabetes mellitus ${ }^{11}$, high levels of alcohol consumption ${ }^{12}$ and physical inactivity ${ }^{13}$ increases risk of BPH development. The obstructive symptoms includes the urinary hesistancy, delay in initiating micturition, intermittency, involuntary interruption of voiding, weak urinary stream, straining to void, a sensation of incomplete emptying, and terminal dribbling. The irritating or storage symptoms on the other hand are urinary frequency, nocturia, urgency, incontinence and bladder pain or dysuria. 
However, prostatic hypertrophy process involves all four cell types namely smooth muscle cells, fibroblast, acinar and basal epithelium with some hormones like growth factors and receptors. ${ }^{14}$ These affirms that $\mathrm{BPH}$ is an endocrine disease. In matured male, testicular androgens is said to regulate growth, development and functional maintenance of the prostratic glands. Also androgens tends to regulate (PSA) prostatic specific antigen secretion by epithelial acinar cells. This PSA a serine protease derivatives is produced by benign and malignant prostatic epithelium, as is a marker for BPH and cancer of prostrate. This is often seen in benign inflammatory disorders of prostrate. ${ }^{15}$ The pathophysiology of this hyperplasia is dependent on the bioavailability of testosterone and its metabolite, dihydrotesterone ${ }^{16}$. Also congenital deficiency of 5 alpha reductase will lead to vestigial prostatic gland ${ }^{17}$ and castration consequently resulting to glandular atrophy/lower urinary tract symptoms regression. ${ }^{18}$ Other factors like high levels of dehydroepiandrosterone, estradiol and insulin-like growth factors are risk factors for formation of BPH. ${ }^{19,20}$

Finally, is well known that bladder dysfunction plays a role in some, if not most of the BPH - related signs and symptoms as that have suggested the use pharmacopies that stimulates the bladder example antimuscuranics with calcium antagonistic may improve storage urinary symptoms. Recently, use of alpha blocker and antimuscuranic agents is now used once bladder outlet is related to BPH and co-exist with overactive bladder symptoms. Hence, combination treatment to decrease resistance to urine outflow through prostatic urethra and increase bladder smooth muscle may assist in bladder outlet surgery success and in detrusor hypocontractility.

\section{Materials and Method:}

A cross sectional study of all histologically 463 diagnosed sample of prostrate sent and reported as benign prostatic hyperplasia were retrieved from the dept. report register from January 2005 to December 2012. They were analyzed using SPSS version 16 while considering the age range, number of occurrence/percentages on each year respectively.

III. Results:

\begin{tabular}{|c|c|c|c|c|c|}
\hline & & Frequency & Percent & Valid Percent & Cumulative Percen \\
\hline \multirow[t]{5}{*}{ Valid } & $40-50$ years & 2 & 2.0 & 3.9 & 3.9 \\
\hline & $50-60$ years & 21 & 21.0 & 41.2 & 45.1 \\
\hline & $60-70$ years & 21 & 21.0 & 41.2 & 86.3 \\
\hline & Above 70 years & 7 & 7.0 & 13.7 & 100.0 \\
\hline & Total & 51 & 51.0 & 100.0 & \\
\hline \multirow[t]{2}{*}{ Missing } & System & 49 & 49.0 & & \\
\hline & Total & 100 & 100.0 & & \\
\hline
\end{tabular}

Histologic Review of Benign Prostatic Hyperplasia in 2005

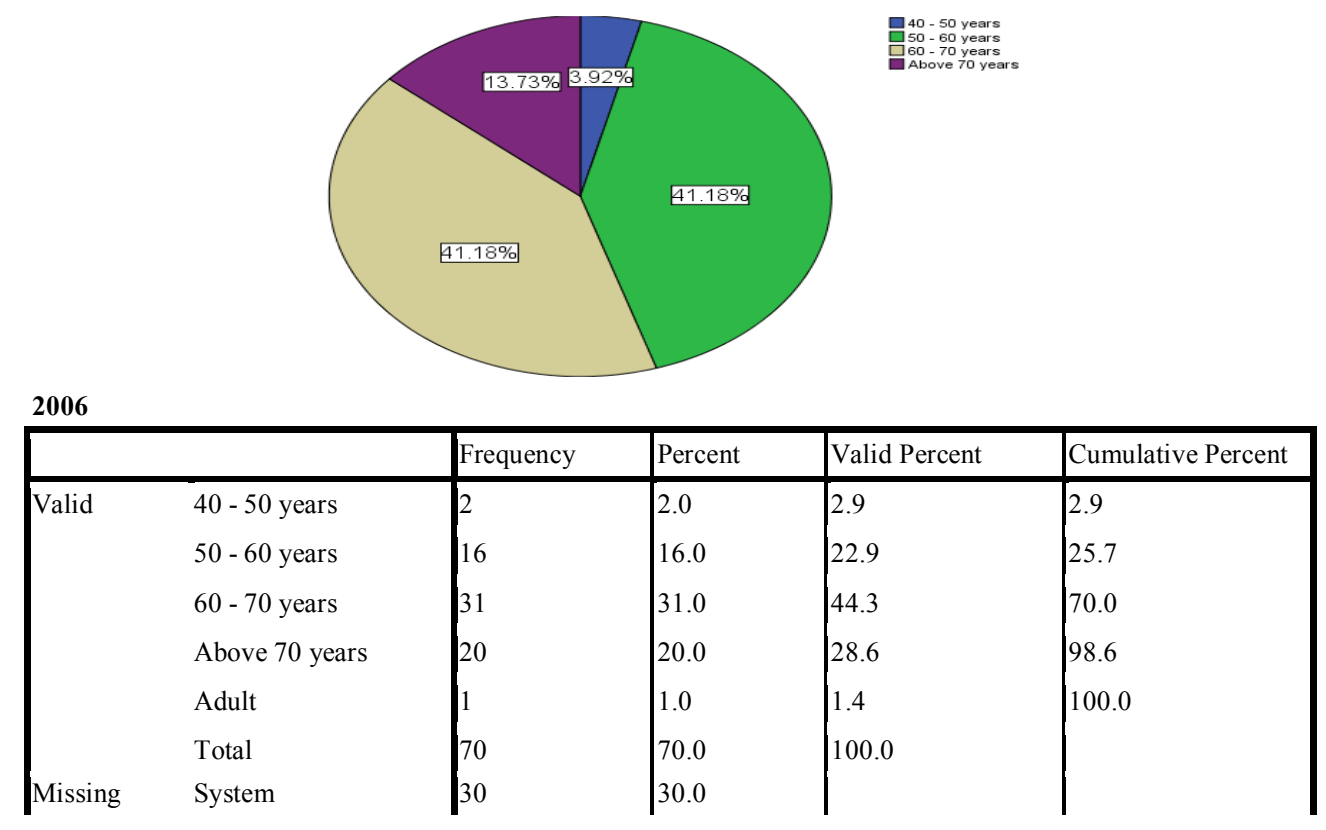

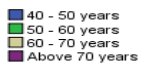




\begin{tabular}{|ll|l|l|l|l|}
\hline 2006 & Frequency & Percent & Valid Percent & Cumulative Percent \\
\hline Valid & 40 - 50 years & 2 & 2.0 & 2.9 & 2.9 \\
& $50-60$ years & 16 & 16.0 & 22.9 & 25.7 \\
& 60 - 70 years & 31 & 31.0 & 44.3 & 70.0 \\
& Above 70 years & 20 & 20.0 & 28.6 & 98.6 \\
& Adult & 1 & 1.0 & 1.4 & 100.0 \\
Missing & Total & 70 & 70.0 & 100.0 & \\
Total & System & 30 & 30.0 & & \\
\hline
\end{tabular}

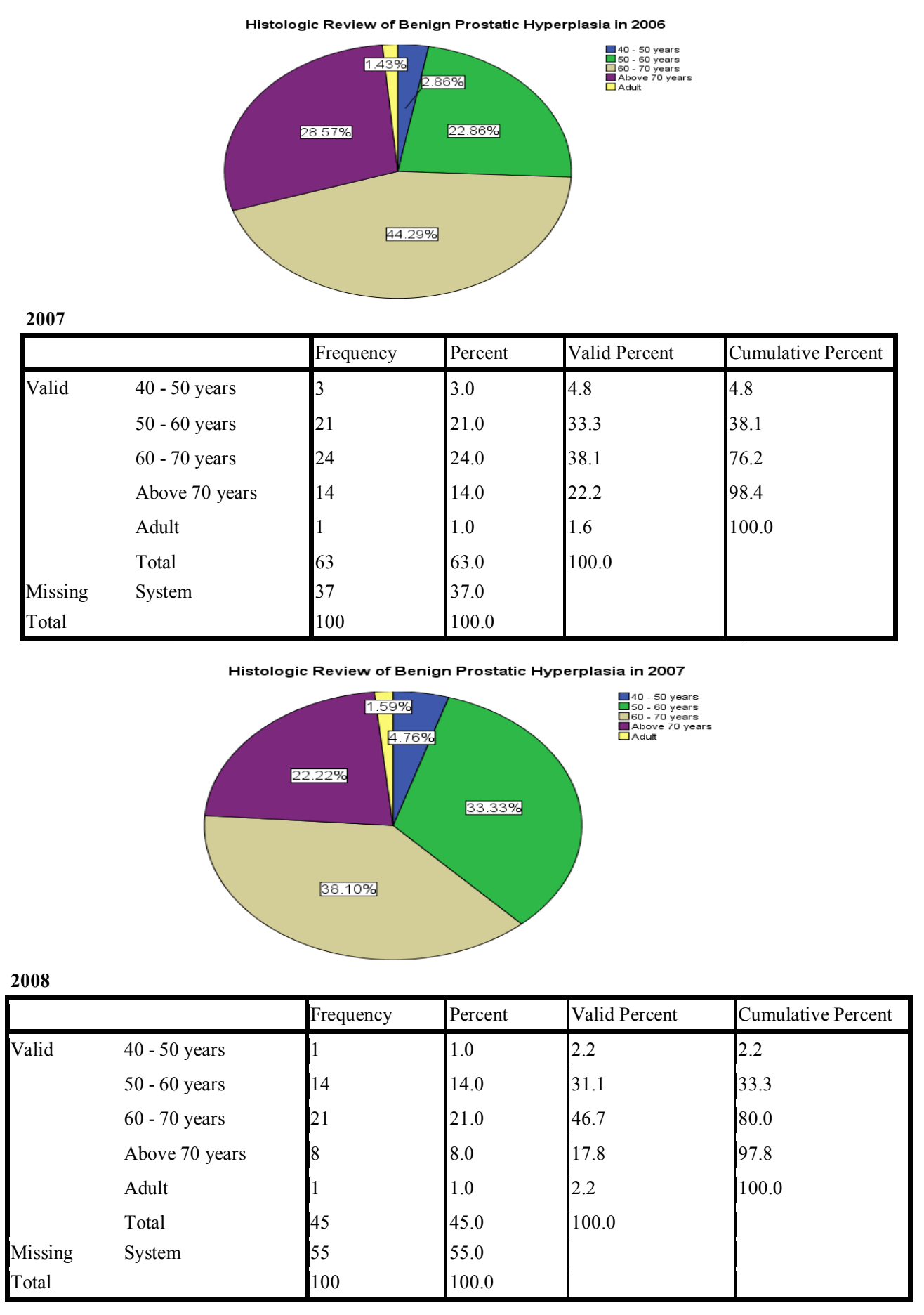




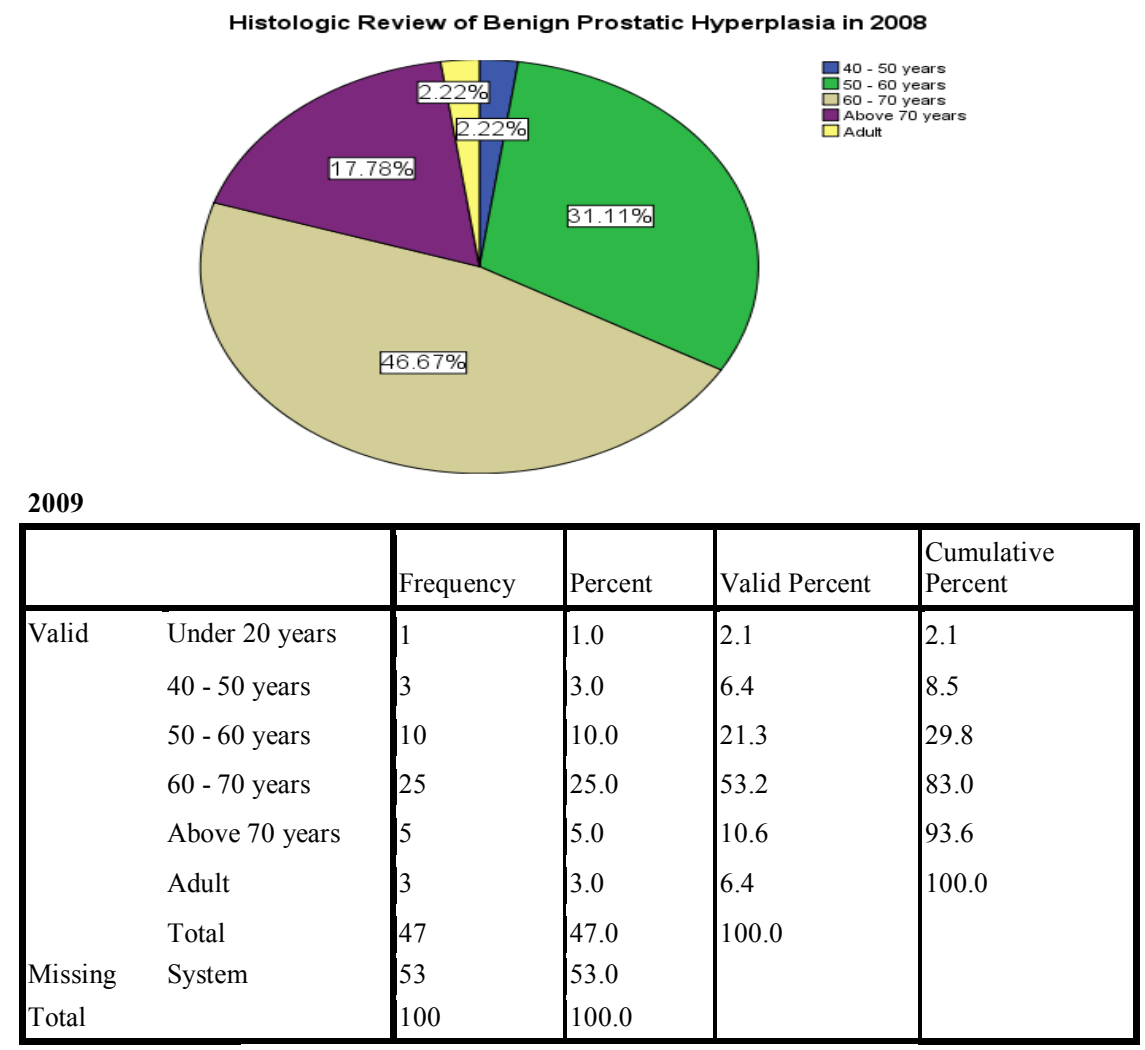

Histologic Review of Benign Prostatic Hyperplasia in 2009
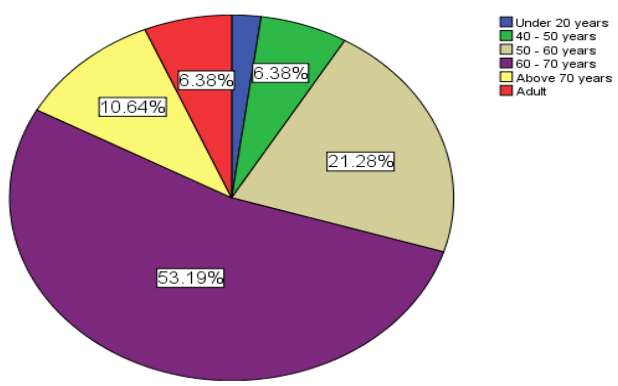

2010

\begin{tabular}{|ll|l|l|l|l|}
\hline & Frequency & Percent & Valid Percent & Cumulative Percent \\
\hline Valid & 40 - 50 years & 5 & 5.0 & 11.9 & 11.9 \\
& $50-60$ years & 9 & 9.0 & 21.4 & 33.3 \\
& 60 - 70 years & 19 & 19.0 & 45.2 & 78.6 \\
& Above 70 years & 9 & 9.0 & 21.4 & 100.0 \\
& Total & 42 & 42.0 & 100.0 & \\
Missing & System & 58 & 58.0 & & \\
Total & & 100 & 100.0 & & \\
\hline
\end{tabular}

Histologic Review of Benign Prostatic Hyperplasia in 2010

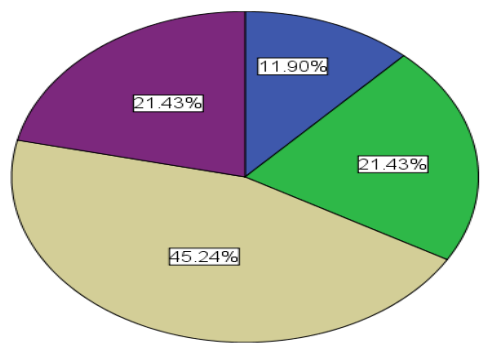

号50-50 years
$50-60$ years
吕 60 - 70 years
Abowe 70 years 


\begin{tabular}{|ll|l|l|l|l|}
\hline 2011 & Frequency & Percent & Valid Percent & Cumulative Percent \\
\hline Valid & 30 - 40 years & 2 & 2.0 & 3.1 & 3.1 \\
& $40-50$ years & 2 & 2.0 & 3.1 & 6.2 \\
& $50-60$ years & 18 & 18.0 & 28.1 & 34.4 \\
& 60 - 70 years & 29 & 29.0 & 45.3 & 79.7 \\
& Above 70 years & 13 & 13.0 & 20.3 & 100.0 \\
Missing & Total & 64 & 64.0 & 100.0 & \\
Total & System & 36 & 36.0 & & \\
\hline
\end{tabular}

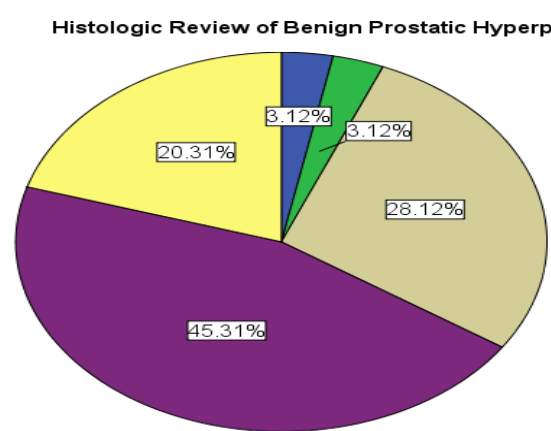

\begin{tabular}{|ll|l|l|l|l|}
\hline \multicolumn{2}{|c|}{} & Frequency & Percent & Valid Percent & Cumulative Percent \\
\hline Valid & Under 20 years & 1 & 1.0 & 1.2 & 1.2 \\
& 40 - 50 years & 1 & 1.0 & 1.2 & 2.5 \\
& $50-60$ years & 19 & 19.0 & 23.5 & 25.9 \\
& 60 - 70 years & 37 & 37.0 & 45.7 & 71.6 \\
& Above 70 years & 22 & 22.0 & 27.2 & 98.8 \\
& Adult & 1 & 1.0 & 1.2 & 100.0 \\
& Total & 81 & 81.0 & 100.0 & \\
Missing & System & 19 & 19.0 & & \\
Total & & 100 & 100.0 & & \\
\hline
\end{tabular}

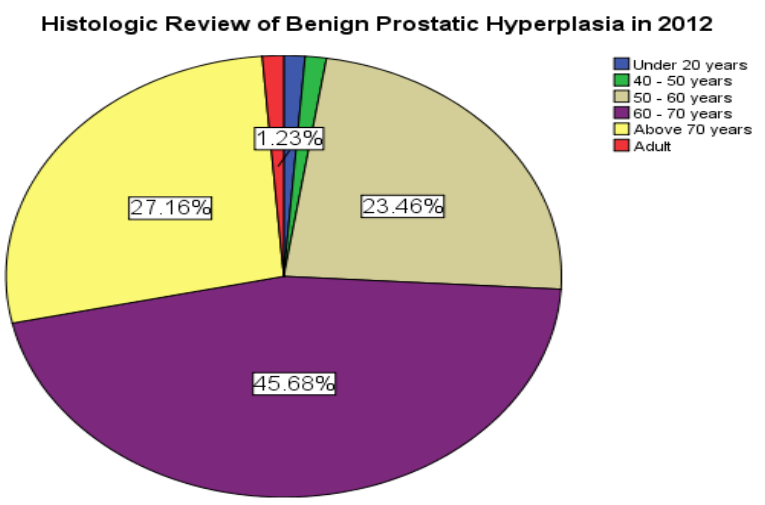

It showed the most vulnerable age of the lesion to be 50-60 years in all the years of study. As this is the commonest age range that had benign prostatic hyperplasia within the seven years of study. This is closely followed by $60-70$ years. The least being above 70 years. However, it is significant to note that a few are of no age/specificity in almost all the years of study. As they appear as inscription of adult at age column which does not place them within any age range of the study.

\section{Discussion/Conclusion:}

It is well known that the age range of 50-60 years appears to be the more vulnerable in all the years of the study when most patients had benign prostatic hyperplasia. Above 60 years we still had the lesions recorded 
and at greater than 70 years a few were seen. This is also same experience in most studies as is known that age is an important risk factor in urinary retention with consequent gradual enlargement of the prostrate.

Roehrborn C.G et $\mathrm{al}^{21}$ found that men diagnosed with BPH,urinary retention (UR) risk increases with aging as 1 in 10 at age of 70 s will experience urinary retention within the next 5 years. This increases to 1 in 3 for men in 80s. Its generally believed that higher rates of UR in older men is due to weakening detrusor functions. ${ }^{22}$ This is also supported by Steve A. Kaplan who said that prostatic enlargement is more commoner as men ages; and more than half in men aged 50 and 60 years. However, these patients are often seen because of lower urinary tract symptoms or by digital examination showing enlarged prostrate or by elevated PSA as a routine examination. ${ }^{23}$ Carl K. Gjertson et al also affirmed that prevalence of BPH increases with age as $25 \%$ of men older than 40 years experience BPH symptoms and this increases about $1 / 3$ of men older than 65 years. ${ }^{24}$ These gets from moderate to severe symptoms from $13 \%$ greater in men of 40 s to $28 \%$ older than 70 years of age. ${ }^{24}$ Finally, a better understanding of all risk factors and rates of clinical progression of BPH helps in medical therapy of patients. Since urinary retention is one of the most usual and significant complications of long term benign prostrate hyperplasia; as risk is cumulative with increasing age which calls for both conservative and surgical therapy.

\section{References:}

[1]. Umtergasser G et al.: Benign Prostatic Hyperplasia: age related tissue-remodelling. Exp geroistol 2005.40:121

[2]. Berry SJ,Coffey DS, Walsh PC, Ewing LL. The development of human benign prostatic hyperplasia with age. J Uol 1984;132:474479

[3]. Chute CG, Panser LA, Girman CJ et al. The prevalence of Prostatism : a population of based Survey of Urinary symptoms. J. urol 1993;150: 85-89.

[4]. Little John JO J, Ghafar MA, Kang YM, Kaplan SA. Trans urethral resection of Prostrate: the new standard. Curr opin Urol 2002;12:19-23.

[5]. Ziada A, Rosenblum M,Crawford Ed. BPH: an overview. Urology 1999;53(suppl 39):1-6.

[6]. Cabelin MA,Te AE, Kaplan SA. BPH: Challenges for the new mellenium.Curr opin urol 2000;10: 301-306.

[7]. Gades NM, Jacobson DJ, Girman CJ et al. Prevalence of conditions potentially associated with lower urinary Tract symptoms in men. 2005.BJU int. 95: 549-553.

[8]. Issa M, Marshall FF: Contemporary diagnosis and Management of diseases of prostrate $3^{\text {rd }}$ edition. 2005 Newton, Pa, Handbooks in health care co.

[9]. Kristal AR. Arnold $\mathrm{Kb}$ et al. Race/ethnicity, obesity,health related behaviours and risk of symptomatic BPH: results from the prostrate cancer prevention Trial. J urol 2007;177,1395-400.

[10]. Giovannucci E. Rimm EB et al. Obesity and BPH. Am J Epidemiol 1994;140:989-1002.

[11]. Sarma AV, St. sawer JL et al. Diabetes treatment and progression of benign prostatic hyperplasia in community-dwelling black and white men. Urology 2012;79:102-8.

[12]. Parsons JK, Im R. Alcohol consumption is associated with a decreased risk of benign postatic hyperplasia. J Urol 2009;182: 1463-8

[13]. Platz EA, Karachi I et al. Physical activity and benign Prostatic hyperplasia. Arch. Intern Med 1998;158:2349-56.

[14]. Levine AC. Pathogenesis and medical management of benign prostatic hyperplasia. Trends endocrinol Metab. 1995;6:128-132.

[15]. Teillac P, Peiret C, Najean Y et al. Prostrate Specific antigen in prostatic Pathology. Ann urol ( Paris) 1988;22:193-196.

[16]. Bartsch G, Rittmaster RS, Klocker H. Dihydrotesterone and the concept of 5 alpha -reductase inhibition in human benign hyperplasia. Euro Urol 2000;37:367-80

[17]. Imperato-McGinley J,Guerrerol L, Gantier $\mathrm{T}$ et al. Steroid 5 alpha-reductase deficiency in man: an inherited form of male pseudohermaphroditism. Science 1974;186:1213-5

[18]. Huggins C, Clark PJ. Quantitative studies of Prostatic secretion 11. The effect of castration and estrogen injection on the normal and on the hyperplastic prostrate glands of dogs. J Exp Med. 1940;72:747-62.

[19]. Nenhouser ML, Kristol AR et al. Steroid Hormones and hormone related genetic and lifestyle characteristics as risk factors for benign prostatic hyperplasia: review of epidermiologic literature. Urology 2004;64:201-11.

[20]. Rohrmann S,Giovanucci E et al. Association of IGF-1 and IGFBP-3 with lower urinary tract symptoms in Third National health and nutrition examination survey. Prostate 2007;67:1693-8.

[21]. Roehrborn C.G. Acute urinary retention: risks and management. Rev. Urol. 2005;7 suppl 4: 531-41

[22]. Jacobsen SJ, Jacohson DJ, Girman CJ et al: Natural history of Prostatism: risk factors for acute urinary retention. J urol. 1997; $158: 481-7$

[23]. Steve A. Kaplan. Identification of the patient with enlarged Prostrate: diagnosis and guidelines for management. Osteopathic medicine and Primary care 2007,1:11 doi:10,1186/1750-4732-1-11.

[24]. Carl K. GJertson et al. Benign Prostatic Hyperplasia: Now we can begin to Tailor treatment. Cleverland Clinic Journal of Medi cine 2004,vol 71 number 11. 